\title{
Influence of Helium and Nitrogen Gases on the Properties of Cold Gas Dynamic Sprayed Pure Titanium Coatings
}

\author{
Wilson Wong, Eric Irissou, Anatoly N. Ryabinin, Jean-Gabriel Legoux, and Stephen Yue
}

\author{
(Submitted May 5, 2010; in revised form September 9, 2010)
}

\begin{abstract}
This study investigates the effect of propellant gas, helium, and nitrogen during cold spraying of titanium coatings. Coatings were characterized by SEM and were evaluated for their deposition efficiency (DE), microhardness, and porosity. In selected conditions, three particle velocities were investigated in which for each condition, the propelling gases' temperature and pressure were attuned to attain similar particle velocities for each gas. Observations show that loosely bonded particles can be detached by high-pressure supersonic gas stream. Selected coatings were characterized by XPS to analyze the occurrence of oxidation and nitridation. Although generally accepted that coating characteristics can be affected by particle temperature, results show that for the same particle velocity, DE and coating density are also a function of substrate temperature. In addition, a thick and fully dense cold sprayed titanium coating was achieved with optimized spray parameters and nozzle using helium. The corresponding average particle velocity was $1173 \mathrm{~m} / \mathrm{s}$.
\end{abstract}

Keywords cold spray, gun traverse speed, helium, nitrogen, substrate temperature, titanium, XPS

\section{Introduction}

Energy efficiency and emission reductions in automobiles and aircrafts can be made possible through the use of titanium (Ti) and its alloys owing to their tremendous potential for weight savings (Ref 1-4). Consequently, it is a major interest for researchers to develop low-cost methods for non-thermal spray forming titanium-based materials to avoid detrimental effects caused by high-temperature processing (i.e., large residual stresses and phase transformations) (Ref 5). In this context, cold spray technology is being investigated ( $\operatorname{Ref} 2,3,5,6)$. This process uses high-pressure compressed gas to propel micron-sized particles onto a substrate under atmospheric conditions (Ref 7-10). Such

This article is an invited paper selected from presentations at the 2010 International Thermal Spray Conference and has been expanded from the original presentation. It is simultaneously published in Thermal Spray: Global Solutions for Future Applications, Proceedings of the 2010 International Thermal Spray Conference, Singapore, May 3-5, 2010, Basil R. Marple, Arvind Agarwal, Margaret M. Hyland, Yuk-Chiu Lau, Chang-Jiu Li, Rogerio S. Lima, and Ghislain Montavon, Ed., ASM International, Materials Park, OH, 2011.

Wilson Wong and Stephen Yue, Department of Mining and Materials Engineering, McGill University, Montreal, QC, Canada; Eric Irissou and Jean-Gabriel Legoux, Industrial Materials Institute, National Research Council Canada, Boucherville, QC, Canada; and Anatoly N. Ryabinin, Faculty of Mathematics and Mechanics, St. Petersburg University, St. Petersburg, Russia. Contact e-mail: wilson.wong@mail.mcgill.ca.

compressed gases are usually air, nitrogen $\left(\mathrm{N}_{2}\right)$, or helium $(\mathrm{He})$. Current research has demonstrated that higher particle impact velocity enhances the overall quality of Ti cold sprayed coatings, although the velocity required for fully dense titanium coatings using nitrogen as the propelling gas has not been reported yet (Ref 1,10-28). The general approach to attain superior velocity when using nitrogen as the propelling gas is to increase its temperature. However, there are some technical limitations when increasing the inlet temperature. Furthermore, two effects can also occur as a result of an excessive high temperature: oxidation and nitridation. Thus, to obtain comparable particle velocity without increasing the gas temperature, a lighter carrier gas, such as helium is required. However, the cost of helium can be prohibitive for many industrial applications and research is needed to either improve the quality of titanium coatings using nitrogen or reduce the cost of helium usage when it is the propelling gas. As an initial approach to addressing the problem, this study investigated the effect of nitrogen versus helium during cold spray of titanium coatings. Specifically, the velocity of the particles was maintained similar from one gas to another by altering the inlet gas pressure and temperature, and the resulting coating characteristics were examined. In addition, a benchmark coating was produced with the maximum achievable particle velocity using helium with optimized parameters, considering the cold spray system and nozzle configuration limitations.

\section{Experimental}

\subsection{Feedstock Powder}

Commercially available plasma-atomized grade $1 \mathrm{CP}$ titanium powder manufactured by Raymor (Montreal, 
Canada) was used and its chemical composition is given in Table 1. The volume-weighted powder size distribution was measured with a laser diffraction particle size analyzer (LS320, Beckman Coulter, Miami, FL, USA).

\subsection{Cold Spray Parameters and Diagnostics}

The cold spray system used to produce the coatings was a KINETIKS ${ }^{\circledR} 4000$ (Cold Gas Technology, Ampfing, Germany) with the $120 \mathrm{~mm}$ long pre-chamber configuration. Titanium powder was cold sprayed onto $76 \mathrm{~mm}^{2} \times$ $3 \mathrm{~mm}$ thick mild carbon steel square plates with a gun step size of $2 \mathrm{~mm}$ for a total width of $36 \mathrm{~mm}$. These coupons were degreased with alcohol and grit-blasted (grit 24 alumina) prior to spraying. The powder feeding rate was set to approximately $20 \mathrm{~g} / \mathrm{min}$. The varied spray parameters are given in Table 2. Two types of nozzles were used: MOC24 (Cold Gas Technology, Ampfing, Germany) and VH70 (ASB Industries Inc., Barberton, USA). Particle velocity measurements were performed using a time-offlight particle diagnostic system DPV2000 (Tecnar Automation, St-Bruno, QC, Canada) operated in cold particle mode using a laser diode $(7 \mathrm{~W}, \lambda=830 \mathrm{~nm})$ to illuminate the in-flight particles (Ref 29). Schlieren imaging was performed with an in-house built apparatus. Deposition efficiency (DE) was measured for selected conditions shown in Table 2. Prior to and after spraying, the substrate was weighed. With these known weights along with the effective spray time over the substrate, the DE was determined (i.e., deposited over injected particles).

The surface temperature was evaluated according to the method described in Ref 30, 31. Temperature values correspond to the mild steel substrate surface temperature beneath the jet of sprayed particles, considering only the heat input from the supersonic gas jet. Additional heat

Table 1 Chemical composition of $\mathrm{CP}$ titanium powder (Mass \%)

\begin{tabular}{lccccccc}
\hline $\mathbf{N}$ & $\mathbf{H}$ & $\mathbf{A l}$ & $\mathbf{N i}$ & $\mathbf{C}$ & $\mathbf{C r}$ & $\mathbf{V}$ & $\mathbf{S i}$ \\
\hline 0.0042 & 0.0051 & 0.01 & 0.01 & 0.01 & 0.01 & 0.02 & 0.03 \\
\hline $\mathbf{F e}$ & $\mathbf{O}$ & $\mathbf{N a}$ & $\mathbf{C u}$ & $\mathbf{T h}$ & $\mathbf{W}$ & Other elements & $\mathbf{T i}$ \\
\hline 0.12 & 0.141 & $<0.01$ & $<0.01$ & $<0.01$ & $<0.01$ & $<0.1$ &
\end{tabular}

input that arises from particle impact and deformation has not been taken into account in the given surface temperature values in Table 2. Impacting titanium particle temperature was evaluated from equations annotated by Stoltenhoff et al. (Ref 32). The transformed equations are presented below:

$\frac{\mathrm{d} v_{\mathrm{p}}}{\mathrm{d} t}=\frac{3}{4} C_{\mathrm{D}} \frac{\rho_{\mathrm{g}}\left(v_{\mathrm{g}}-v_{\mathrm{p}}\right)\left|v_{\mathrm{g}}-v_{\mathrm{p}}\right|}{\rho_{\mathrm{p}}}$

$\frac{\mathrm{d} x}{\mathrm{~d} t}=v_{\mathrm{p}}$

$\frac{\mathrm{d} T_{\mathrm{p}}}{\mathrm{d} t}=\frac{6 N u k}{D^{2} \rho_{\mathrm{p}} c_{\mathrm{p}}}\left(T_{\mathrm{g}}-T_{\mathrm{p}}\right)$

where $v_{\mathrm{p}}$ and $v_{\mathrm{g}}$ are the particle and gas velocities, $\rho_{\mathrm{p}}$ and $\rho_{\mathrm{g}}$ are the particle and gas densities, respectively, $D$ is the particle diameter, $x$ is the particle coordinate, $T_{\mathrm{p}}$ and $T_{\mathrm{g}}$ are the particle and gas temperatures, $k$ is the thermal conductivity of the carrier gas, and $c_{\mathrm{p}}$ is the particle specific heat capacity. The drag coefficient of spherical particles, $C_{\mathrm{D}}$, is a function of Reynolds $(R e)$ and Mach $(M a)$ numbers. The formula for $C_{\mathrm{D}}$ was taken from Henderson (Ref 33). The Nusselt $(\mathrm{Nu})$ number, which is a function of Reynolds $(R e)$, Prandtl $(P r)$, and Mach $(M a)$ numbers, was taken from Stoltenhoff et al. (Ref 32). Gas parameters such as temperature and density were calculated on the basis of a one-dimensional isentropic model. Finally, the Runge-Kutta method was used to solve the impacting titanium particle temperature from the system of equations described above. In order to confirm the validity of these derived equations, impacting particle temperatures for copper particles assuming the same spray parameters as provided in the work by Stoltenhoff et al. (Ref 32) were calculated. These results were consistent with those presented in their article (Ref 32).

\subsection{Metallographic Preparation and Examination}

For coating cross-section observations, coupons were sectioned with a coolant-assisted diamond wheel. Sectioned coatings and a slight amount of powder were then cold vacuum mounted in an epoxy resin and ground then polished using standard metallographic preparation procedures.

Table 2 Experimental Parameters

\begin{tabular}{|c|c|c|c|c|c|c|c|c|c|c|}
\hline Condition & $\begin{array}{l}\text { Carrier } \\
\text { gas }\end{array}$ & $\begin{array}{c}\text { Gas pressure, } \\
\text { MPa }\end{array}$ & $\begin{array}{c}\text { Gas temp., } \\
{ }^{\circ} \mathrm{C}\end{array}$ & $\begin{array}{c}\text { Stand-off } \\
\text { distance, cm }\end{array}$ & $\begin{array}{c}\text { Traverse } \\
\text { speed, } \mathbf{m m} / \mathbf{s}\end{array}$ & $\begin{array}{l}\text { Number } \\
\text { of passes }\end{array}$ & Nozzle & $\begin{array}{c}\text { Particle } \\
\text { velocity, } \mathrm{m} / \mathrm{s}\end{array}$ & $\begin{array}{l}\text { Substrate } \\
\text { temp., }{ }^{\circ} \mathrm{C}\end{array}$ & $\begin{array}{c}\text { Particle } \\
\text { temp., }{ }^{\circ} \mathrm{C}\end{array}$ \\
\hline $1_{N_{2}}$ & $\mathrm{~N}_{2}$ & 3 & 300 & 4 & 330 & 10 & MOC24 & 608 & 45 & 128 \\
\hline $1_{\mathrm{He}}$ & $\mathrm{He}$ & 0.5 & 100 & 4 & 330 & 10 & MOC24 & 604 & 35 & -154 \\
\hline $2 \mathrm{~N}_{2}$ & $\mathrm{~N}_{2}$ & 3 & 600 & 4 & 330 & 10 & MOC24 & 688 & 110 & 333 \\
\hline $2 \mathrm{He}$ & $\mathrm{He}$ & 0.75 & 70 & 4 & 330 & 10 & MOC24 & 690 & 31 & -155 \\
\hline $3 \mathrm{~N}_{2}$ & $\mathrm{~N}_{2}$ & 4 & 800 & 4 & 330 & 10 & MOC24 & 805 & 140 & 466 \\
\hline $3_{\mathrm{He}}$ & $\mathrm{He}$ & 1.4 & 50 & 4 & 330 & 10 & MOC24 & 812 & 29 & -150 \\
\hline $4_{\text {Fast }}$ & $\mathrm{N}_{2}$ & 4 & 800 & 4 & 150 & 30 & $\mathrm{MOC} 24$ & 805 & 186 & 466 \\
\hline $4_{\text {Slow }}$ & $\mathrm{N}_{2}$ & 4 & 800 & 4 & 5 & 1 & MOC24 & 805 & 496 & 466 \\
\hline $5^{10 w}$ & $\mathrm{He}$ & 4 & 350 & 8 & 330 & 10 & VH70 & 1173 & 73 & $\mathrm{~N} / \mathrm{A}$ \\
\hline
\end{tabular}


Microstructural observations were performed using a light optical microscope (LOM), a JEOL 840 scanning electron microscope (SEM), and a field emission gun scanning electron microscope Hitachi S-4700 (FEG-SEM). LOM was used to examine etched powder cross-sections and to perform average coating thickness measurements. The etchant used was diluted Kroll's $\left(100 \mathrm{~mL} \mathrm{H}_{2} \mathrm{O}, 5 \mathrm{~mL}\right.$ $\mathrm{HNO}_{3}$, and $2 \mathrm{~mL} \mathrm{HF}$ ). SEM secondary electron imaging was employed to characterize as-polished powder crosssections, while back-scattered electron imaging was used to measure coating cross-section porosity. The latter was accomplished using image analysis software on as-polished samples. For each specimen, a minimum of ten random images were taken and then evaluated for porosity. All coatings were artificially divided in two halves (top, away from the substrate; and bottom, adjacent to the substrate) and were evaluated for porosity independently. FEG-SEM secondary electron imaging was used to observe the feedstock powder and the top surface layers of as-sprayed coatings, while back-scattered imaging was used to characterize coating cross-sections. Microhardness measurements were performed on mounted and as-polished samples with a Buehler Micromet II Tester according to ASTM standard E384-99. All tests were implemented under $10 \mathrm{~g}$ loads for a penetration time of $15 \mathrm{~s}$. For each specimen, a minimum of 12 indentations were performed and the average value was used as an indicator of coating microhardness. As with the porosity measurements, all coatings were artificially separated in two halves and each region was evaluated for microhardness independently, except for conditions $4_{\text {Fast }}$ and $4_{\text {Slow }}$ since the area of interest for these single line coatings was located near the interface between the deposit and the substrate. In addition, a 220i XL from FISONS Instruments (East Grinstead, West Sussex, UK) was used to perform x-ray photoelectron spectroscopy (XPS) on the coating cross-sections for conditions $4_{\text {Fast }}$ and $4_{\text {Slow }}$ to ascertain the occurrence of oxidation or nitridation.

\section{Results and Discussion}

\subsection{Feedstock Powder Characterization}

Figure 1 shows the $\mathrm{CP}$ titanium particle size distribution with volume as the distribution base. Analysis of the feedstock powder revealed that the mean particle size was $29 \mu \mathrm{m}$ and the average microhardness was $141 \mathrm{HV}$. Figure 2(a) shows the spherical morphology of the plasma atomized titanium powder. Figure 2(b), an as-polished cross-section, revealed that the particles were non-porous, and Fig. 2(c), the etched cross-section of the powder exhibited an acicular $\alpha$ structure that is common in atomized pure titanium powder.

\subsection{Effect of Propelling Gas Nature}

In order to investigate the effect of the nature of propellant gas used during cold sprayed titanium coatings, experimental parameters were adjusted so that the

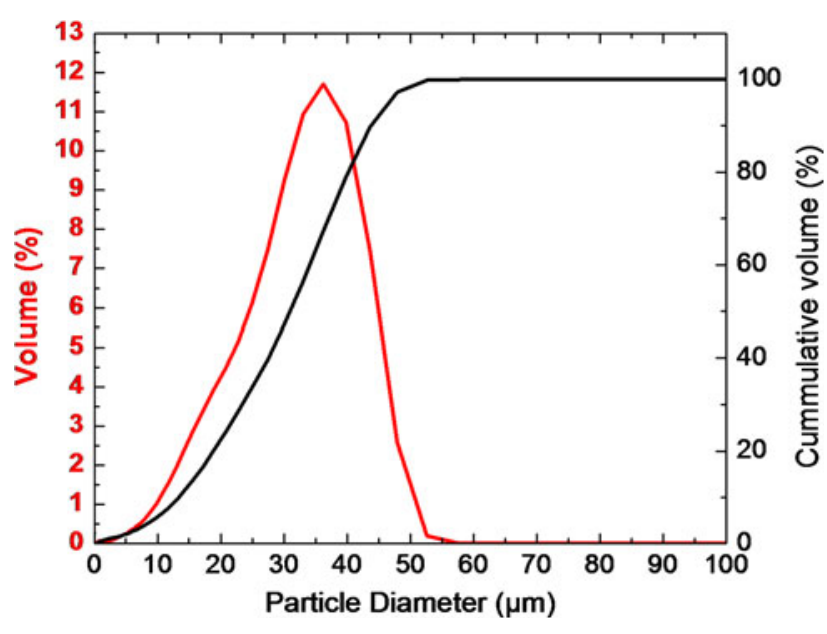

Fig. 1 CP titanium particle size distribution

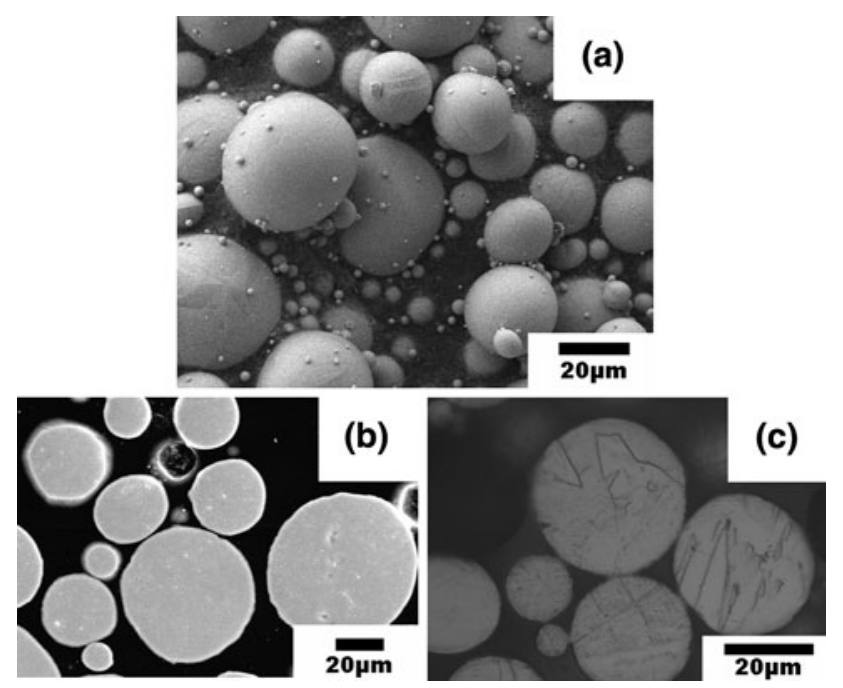

Fig. 2 (a) SEM micrograph depicting the morphology of the spherical titanium powder, (b) as-polished, and (c) etched powder cross-section

average particle velocity remained similar between nitrogen and helium trials for velocity conditions 1,2 , and 3 . These parameters are described in Table 2. Furthermore, for samples sprayed with $\mathrm{N}_{2}$, the ambient atmosphere was air, while with $\mathrm{He}$ the atmosphere was mainly $\mathrm{He}$ as a consequence of using a gas-tight spray room with a helium recovery system (HRS) as presented in detail by Legoux et al. (Ref 34). For each condition, even though the average particle velocity was approximately the same, the velocity distribution differs, as shown in Fig. 3(a-c). The standard deviation with $\mathrm{He}$ was larger than with $\mathrm{N}_{2}$, most likely due to differences in drag forces.

Figure 4(a-c) represents cross-sections of coatings sprayed with $\mathrm{N}_{2}$, while Fig. 4(d-f) represents the corresponding as-sprayed coating surface top views. Figure 5(af), analogous to Fig. 4(a-f), represents samples sprayed with He. Table 3 displays the characterization results, including DE, porosity, average coating thickness, and 


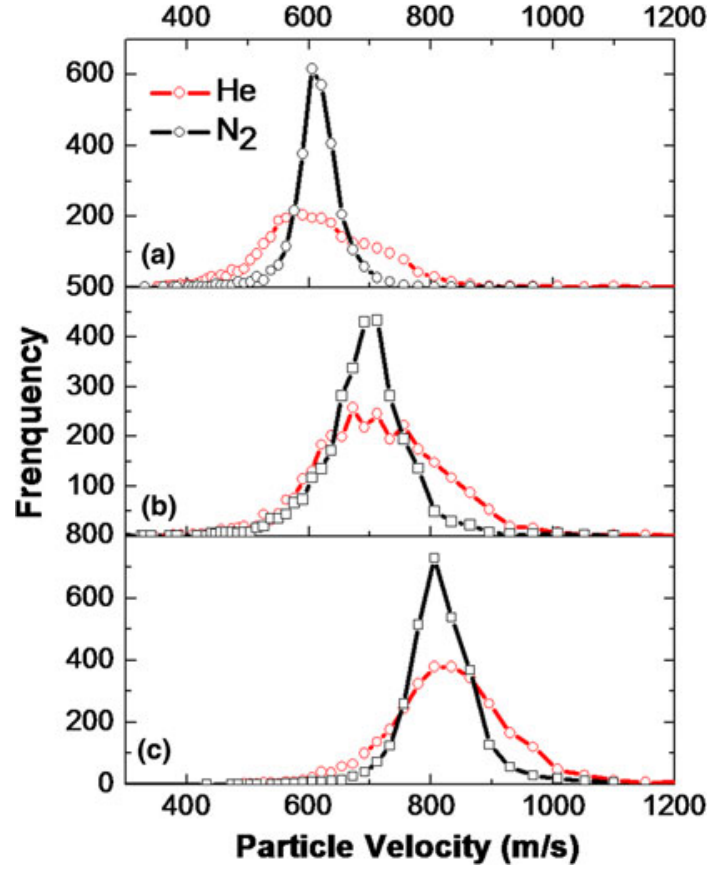

Fig. 3 Particle velocity distributions for conditions (a) $1_{\mathrm{N}_{2}}$ and $1_{\mathrm{He}}$, (b) $2_{\mathrm{N}_{2}}$ and $2_{\mathrm{He}}$, and (c) $3_{\mathrm{N}_{2}}$ and $3_{\mathrm{He}}$

microhardness for conditions 1 to $3\left(\mathrm{~N}_{2}\right.$ and $\left.\mathrm{He}\right)$. The letters " $\mathrm{T}$ " and "B" correspond to the top and bottom regions of the coatings for both porosity and microhardness values, respectively, as described in section 2 .

As described in detail elsewhere $(\operatorname{Ref} 4,15,35)$, the faster the particles impinge on the substrate, the higher the DE, coating density, and microhardness. Although produced with the same average particle velocity, obvious microstructural differences can be seen between coatings deposited with $\mathrm{He}$ and with $\mathrm{N}_{2}$ as shown in Fig. 4, 5, and Table 3. For condition 1, the sample produced with $\mathrm{He}$ shows a lower porosity and a higher DE when compared to the sample produced with $\mathrm{N}_{2}$. However, the reverse was observed for conditions 2 and 3 . Close observation of the coating surface revealed several differences between coatings produced with $\mathrm{N}_{2}$ and He. Comparing Fig. 4(e) to 5(e), and 4(f) to 5(f), one can see that the level of consolidated region in between the particles is higher with $\mathrm{N}_{2}$ than with He. For conditions 2 and 3, evidence of material jetting can be seen surrounding several particles on $\mathrm{N}_{2}$ produced coatings while no such evidence can be seen on He-produced coatings. For condition 1, no evidence of material jetting can be seen (Fig. 4d, 5d) and as a result of the lower particle velocity, the level of consolidated region is much less than in conditions 2 and 3 for both He- and $\mathrm{N}_{2}$-produced coatings. The differences in deposition efficiencies cannot be explained solely by the differences in particle velocity distributions. The broader particle velocity distribution with $\mathrm{He}$ resulted in a larger number of slower particles than with $\mathrm{N}_{2}$. As a consequence, a lower DE could be expected. However, the DE with He is higher than that of $\mathrm{N}_{2}$ for condition 1 .
To obtain the same average particle velocity for $\mathrm{He}$ and $\mathrm{N}_{2}$, either or both the inlet gas pressure and temperature had to be significantly different. Increasing inlet gas temperature results in a higher particle temperature as well as a higher substrate temperature due to heat transfer between the propelling gas and the particle (Ref 36$)$ and the substrate (Ref 30, 31), respectively. Between samples produced with $\mathrm{N}_{2}$ and $\mathrm{He}$, the difference in substrate temperature for conditions 2 and 3 were 79 and $111{ }^{\circ} \mathrm{C}$, while the difference in impacting particle temperature for conditions 2 and 3 were 488 and $616^{\circ} \mathrm{C}$. For conditions 2 and 3, the higher DE and lower porosity obtained with $\mathrm{N}_{2}$ could be explained by the higher surface and/or impacting particle temperature during deposition with $\mathrm{N}_{2}$. Indeed, higher surface temperature and/or impacting particle temperature may allow for easier particle deformation upon impact because the substrate and/or particles are softer and more ductile. This facilitates particle/substrate and particle/particle bonding, thus, improving DE and reducing coating porosity. For condition 1, even though the particle temperature and the substrate temperature were higher for $\mathrm{N}_{2}$, the DE and porosity were worse. In addition, condition 1 had the lowest average substrate surface and particle temperature as well as the lowest average particle velocity in comparison to conditions 2 and 3. Therefore, the bonding mechanisms were more likely due to mechanical anchorages or compaction, as can be seen in Fig. 4(d) and 5(d), which in turn produced more loosely bonded particles at the surface. The lower DE and higher porosity level at condition $1_{\mathrm{N}_{2}}$ could therefore be accounted by the bow shock amplitude difference due to differences in inlet pressure ( $3 \mathrm{MPa}$ vs. $0.5 \mathrm{MPa}$ for condition $1_{\mathrm{He}}$ ). Figure 6 compares Schlieren images obtained for condition 1 at 0.5 and $3 \mathrm{MPa}$. Even though, the Schlieren experiments were performed with $\mathrm{N}_{2}$ at both pressures and given that, with $\mathrm{He}$, the amplitude could be slightly different at $0.5 \mathrm{MPa}$, this comparison clearly illustrates the difference in density gradients and thus, in the pressure applied to the surface of the substrate as a function of inlet gas pressure.

Cold spraying at high pressure ( $3 \mathrm{MPa}$ ) creates a gas jet at the surface of the substrate strong enough to remove typical thermal spray masking tapes, paint, and any low bond strength applied coatings or films. In the case of condition $1_{\mathrm{N}_{2}}$, for every gun pass, loosely bonded particles on top of the coating could have been removed by the high-pressure gas jet. Thus, DE would be reduced. For condition $1_{\mathrm{He}}$, the pressure was much lower and thus, more of the loosely bonded particles at the surface could remain after each pass. To further investigate this hypothesis, the coating surface layers for conditions $1_{\mathrm{N}_{2}}$ and $1_{\mathrm{He}}$ were examined (Fig. $7 \mathrm{a}, \mathrm{b}$, respectively). Visual inspection of these images revealed a noticeably higher number of craters for condition $1_{\mathrm{N}_{2}}$ than $1_{\mathrm{He}}$. These craters (indicated by arrows in Fig. 7a) were produced either by incoming particles that were not able to adhere or were loosely adhered upon impact but were removed by the subsequent gun pass with high gas pressure. From the size of the craters, it could be deduced that the smaller-sized particles were preferentially removed. As previously sta- 

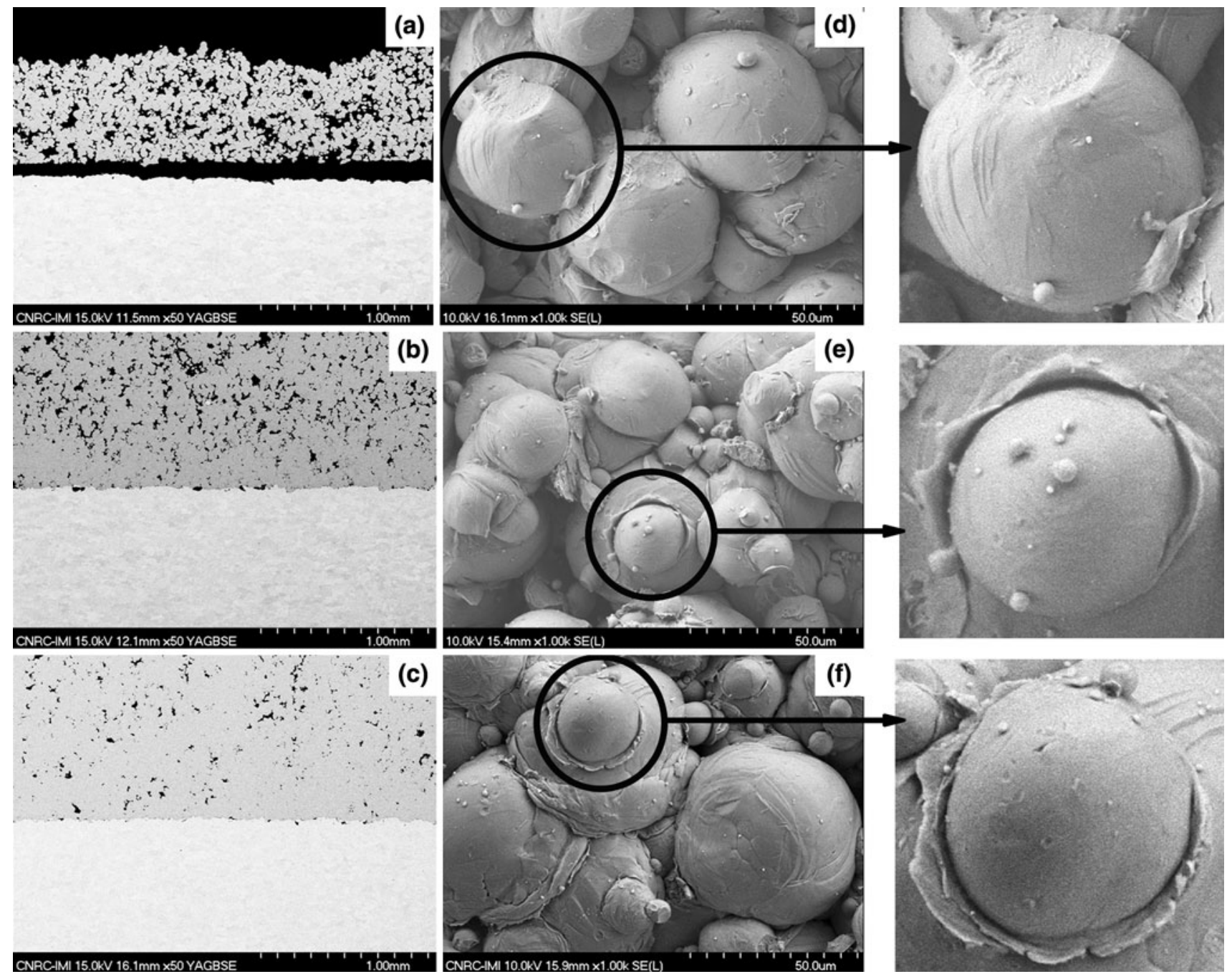

Fig. 4 Coating cross-section and surface top view, respectively, of condition $1_{\mathrm{N}_{2}}$ (a, d), $2_{\mathrm{N}_{2}}$ (b, e), and $3_{\mathrm{N}_{2}}$ (c, f)

ted, the substrate and the particle temperatures were higher for condition $1_{\mathrm{N}_{2}}$ in comparison to $1_{\mathrm{He}}$. This presumably would allow for more plastic deformation to occur; however, this was not the case and the DE and the level of porosity were worse. Since more craters were observed for condition $1_{\mathrm{N}_{2}}$ and given that the particle velocities were similar for both gases, it is reasonable to assume that condition $1_{\mathrm{N}_{2}}$ had more loosely bonded particles which were removed due to the powerful gas stream at $3 \mathrm{MPa}$. For conditions $2_{\mathrm{N}_{2}}$ and $3_{\mathrm{N}_{2}}$, no craters were observed, in agreement with a DE of $100 \%$. This can be attributed to the higher surface and/or impacting particle temperatures, which allows for more plastic deformation to manifest. This in turn could create stronger interparticle bonds which would be more difficult to remove by a vigorous gas jet. In contrast, several craters were observed for conditions $2 \mathrm{He}$ and $3 \mathrm{He}$ and the DE were 70 and $89 \%$, respectively, most likely indicating that weaker interparticle bonding transpired due to the significantly lower substrate and particle temperatures. Once more, these results support the hypothesis that better interparticle bonding would develop with higher surface temperature and/or impacting particle temperature.

Regarding coating porosity, conditions $2 \mathrm{~N}_{2}$ and $3 \mathrm{~N}_{2}$ revealed a lower level of porosity (top and bottom) as opposed to conditions $2 \mathrm{He}$ and $3_{\mathrm{He}}$. This again could be explained by the higher inlet gas temperature, allowing for more plastic deformation and greater material jetting to occur, which in turn helped fill the gaps between adjacent particles. This phenomenon was not as significant for conditions $2 \mathrm{He}$ and $3 \mathrm{He}$ since the inlet gas temperatures were significantly lower. It has been proposed that high strain-rate thermal softening sensitivity is related to the bonding and densification of particles (Ref 35, 37-39). Thermal softening can manifest as a result of adiabatic heating (Ref 37). When thermal softening overcomes strain and strain-rate hardening, instant flow stress breakdown transpires (Ref 39). This allows for more deformation of particles which in turn leads to denser coatings. Since higher inlet gas temperature and greater particle velocity increase the magnitude of adiabatic heating, the probability of the thermal softening surpassing 

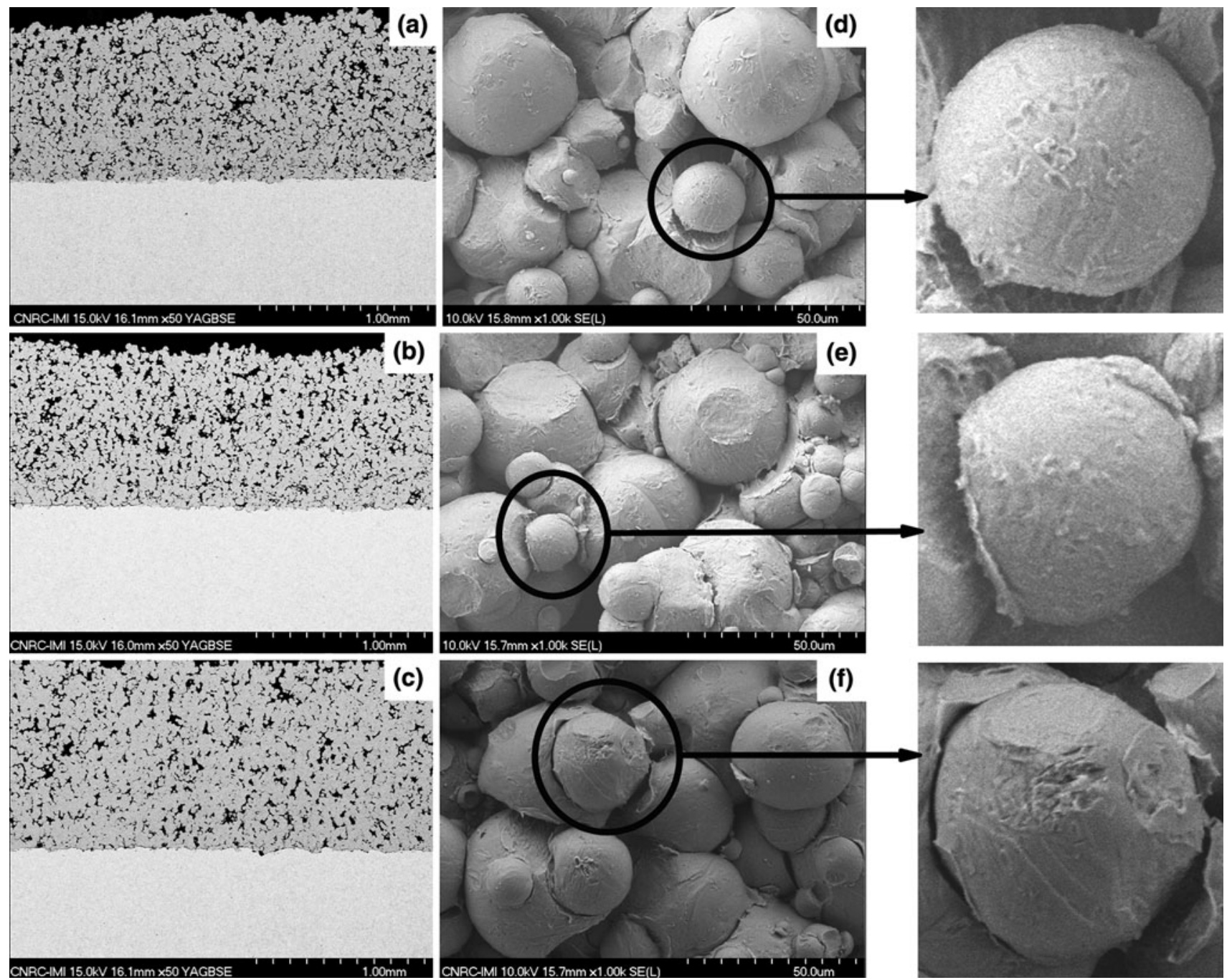

Fig. 5 Coating cross-section and surface top view, respectively, of condition $1_{\mathrm{He}}(\mathrm{a}, \mathrm{d}), 2_{\mathrm{He}}(\mathrm{b}, \mathrm{e})$, and $3_{\mathrm{He}}(\mathrm{c}, \mathrm{f})$

Table 3 Characterization results

\begin{tabular}{|c|c|c|c|c|}
\hline Condition & DE \% & $\begin{array}{c}\text { Porosity, } \\
\%\end{array}$ & $\begin{array}{l}\text { Average coating } \\
\text { thickness, } \mu \mathrm{m}\end{array}$ & $\begin{array}{c}\text { Microhardness, } \\
\text { HV }\end{array}$ \\
\hline $1_{\mathrm{N}_{2}}$ & 47 & $\begin{array}{l}T=20.6 \\
B=19.5\end{array}$ & 605 & $\begin{array}{l}T=190 \\
B=192\end{array}$ \\
\hline $1_{\mathrm{He}}$ & 66 & $\begin{array}{l}T=14.6 \\
B=10.8\end{array}$ & 797 & $\begin{array}{l}T=187 \\
B=188\end{array}$ \\
\hline $2 \mathrm{~N}_{2}$ & 100 & $\begin{array}{l}T=7.8 \\
B=5.0\end{array}$ & 1344 & $\begin{array}{l}T=187 \\
B=203\end{array}$ \\
\hline $2_{\mathrm{He}}$ & 70 & $\begin{array}{l}T=13.2 \\
B=10.2\end{array}$ & 1030 & $\begin{array}{l}T=188 \\
B=194\end{array}$ \\
\hline $3_{\mathrm{N}_{2}}$ & 100 & $\begin{array}{l}T=1.9 \\
B=1.7\end{array}$ & 1172 & $\begin{array}{l}T=205 \\
B=218\end{array}$ \\
\hline $3_{\mathrm{He}}$ & 89 & $\begin{array}{l}T=10.1 \\
B=7.0\end{array}$ & 1064 & $\begin{array}{l}T=188 \\
B=198\end{array}$ \\
\hline
\end{tabular}

the threshold of strain and strain-rate hardening is increased. Thus, enhanced particle deformation and densification would be expected. For condition 1, it stands to
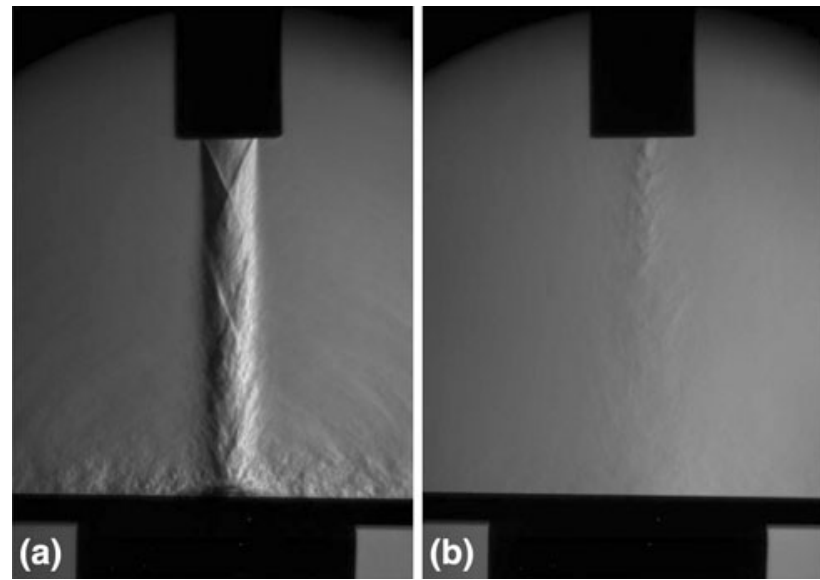

Fig. 6 Schlieren images of cold spray generated supersonic gas flows of nitrogen at an inlet pressure of (a) $3 \mathrm{MPa}$ and (b) $0.5 \mathrm{MPa}$ 

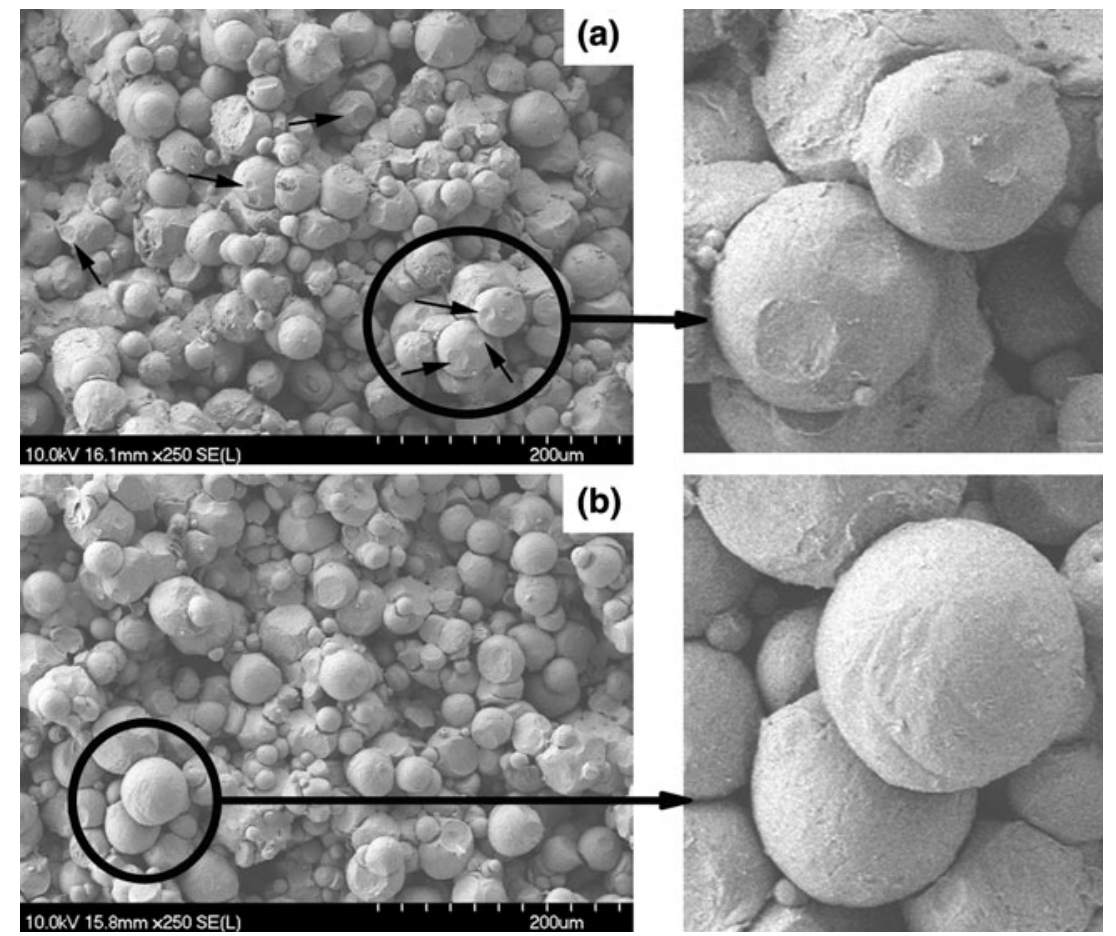

Fig. 7 Surface top view of condition (a) $1_{\mathrm{N}_{2}}$ and (b) $1_{\mathrm{He}}$

reason that the coating produced with $\mathrm{He}$ was denser than the sample produced with $\mathrm{N}_{2}$, since more loosely bonded Ti particles remained attached. These unremoved smaller particles helped reduce the coating pore size by filling in the gaps between other larger particles, as clearly demonstrated in Fig. 8(a) and (b). Microhardness was similar between conditions $1_{\mathrm{N}_{2}}$ and $1_{\mathrm{He}}$ (top and bottom regions), and the top region of conditions $2_{\mathrm{N}_{2}}$ and $2_{\mathrm{He}}$, ranging from 187 to $192 \mathrm{HV}$. These coatings were fairly porous and their cross-section micrographs (Fig. 4a, b, 5a, b) clearly revealed numerous spherically shaped particles, an indication of the lack of plastic deformation. Thus, strain hardening was not as prevalent, particularly when compared to denser coatings, as in conditions $2_{\mathrm{N}_{2}}, 2_{\mathrm{He}}, 3_{\mathrm{N}_{2}}$, and $3_{\mathrm{He}}$. In these situations, the microhardness values significantly increased, ranging from 194 to $218 \mathrm{HV}$. The highest value recorded was $218 \mathrm{HV}$ for condition $3_{\mathrm{N}_{2}}$. Specifically with this condition, a significant amount of material jetting occurred (Fig. 4f). Thus, significant strain hardening would have taken place, which could explain the higher microhardness value observed.

\subsection{Further Investigation on Temperature Effect and $x$-Ray Photoelectron Spectroscopy}

Thus far, it has been shown that higher inlet gas temperature (and consequently, higher substrate surface and impacting particle temperatures) is beneficial for cold sprayed titanium coatings. However, it is impractical to continuously increase the inlet gas temperature due to cold spray system limitations. Hence, to increase the substrate temperature while spraying at a given temperature (e.g., $800^{\circ} \mathrm{C}$ ), the gun traverse speed can be decreased. To demonstrate this, two coupons were produced: conditions $4_{\text {Fast }}$ and $4_{\text {slow. }}$. Both of these conditions include the same experimental parameters as condition $3_{\mathrm{N}_{2}}$, except for three alterations: a different gun traverse speed, a different number of passes, and no gun step size were employed, producing a thick single line coating for each sample. These alterations were selected to produce coatings similar to those of Gulizia et al. (Ref 12) in which they tested the occurrence of oxidation and nitridation on cold sprayed Ti coatings. More details pertaining to the investigation of these parameters occur later in this section. Specifically, condition $4_{\text {Fast }}$ had a gun traverse speed of $150 \mathrm{~mm} / \mathrm{s}$ and 30 passes, while condition $4_{\text {Slow }}$ had a gun traverse speed of $5 \mathrm{~mm} / \mathrm{s}$ and 1 pass. Digital images of the as-sprayed samples are shown in Fig. 9(a-d). On the surface, similar triangular-shaped coatings can be seen for both conditions (Fig. 9a, c). However, it can also be seen that, for condition $4_{\text {slow }}$, the low carbon steel substrate was oxidized in proximity of the coating, indicating that it was submitted to significantly more heat input than for the fast gun traverse speed condition $\left(4_{\text {Fast }}\right)$. Figure 10 reveals the function of particle flow rate and velocity with respect to the radial position from the center of the nozzle (i.e., the center of the particle jet) at an inlet gas $\left(\mathrm{N}_{2}\right)$ of $700{ }^{\circ} \mathrm{C}$. A similar outcome would be expected with other inlet gas temperatures comparable to $700{ }^{\circ} \mathrm{C}$, such as $800{ }^{\circ} \mathrm{C}$. The particle flow rate and velocity are at their maximum at the center of the particle jet and decrease as the particles exit farther away from the center of the nozzle. The triangularshaped coating obtained can therefore be attributed only to the radial distribution in flow rate of spray particles 


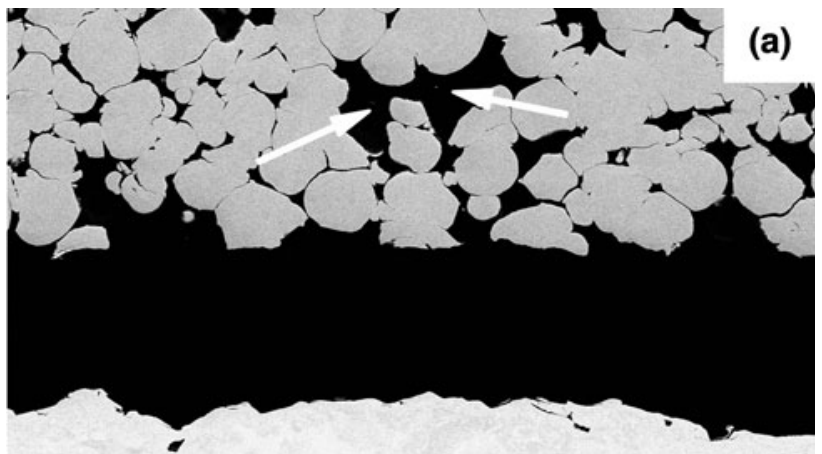

CNRC-IMI $15.0 \mathrm{kV} 11.5 \mathrm{~mm} \times 250$ YAGBSE

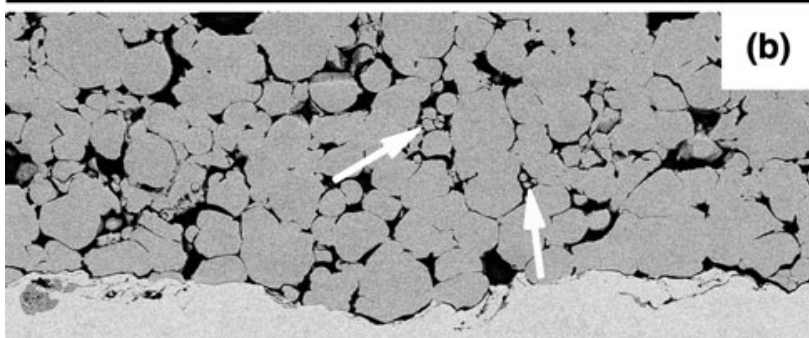

CNRC-IMI 15.0kV $16.1 \mathrm{~mm} \times 250$ YAGBSE

200um

Fig. 8 Coating cross-section of condition (a) $1_{\mathrm{N}_{2}}$ and (b) $1_{\mathrm{He}}$

since in both cases the DE was $100 \%$. Based on the above, the proper microstructural characterization area of a single line coating where different traverse speeds and number of passes are used should be located in the middle of the line coating as illustrated by the rectangle in Fig. 11. This is due to the fact that particles that build the outer part of the coating impinge less and less at right angles due to coating build-up and consequently, their effective impact velocities are lower which result in a more porous region.

Coating cross-sections and surface top views for conditions $4_{\text {Fast }}$ and $4_{\text {Slow }}$ are shown in Fig. 12 (a-d). From these images, one can easily observe that condition $4_{\text {Slow }}$ achieved a denser coating as opposed to $4_{\text {Fast }}$. Porosity measurements confirmed this, where the levels of porosity were 0.1 and $0.9 \%$ for conditions $4_{\text {Slow }}$ and $4_{\text {Fast }}$, respectively. In addition, more material jetting and a larger area of consolidated region surrounding the particles were observed for condition $4_{\text {slow }}$, indicating that a greater degree of plastic deformation of particles occurred. These observations could be explained by the higher substrate surface temperature of $496{ }^{\circ} \mathrm{C}$ for condition $4_{\text {slow }}$ compared to $186{ }^{\circ} \mathrm{C}$ for condition $4_{\text {Fast }}$. It is worth noting here that the gas temperature was identical for both conditions and so, the particle temperature upon impact should have been identical as well. The regular coating sprayed at $330 \mathrm{~mm} / \mathrm{s}$ (condition $3 \mathrm{~N}_{2}$, Fig. 4c, f) was the most porous (approximately 1.8\%) in comparison to the two single line coatings in condition 4 . Two factors influenced the coating quality of condition $3_{\mathrm{N}_{2}}$. First, since the gun traverse speed was $330 \mathrm{~mm} / \mathrm{s}$, the resultant substrate surface temperature was $140{ }^{\circ} \mathrm{C}$, which was the coolest temperature among these coatings. As explained previously, lower substrate surface temperature leads to greater porosity because less plastic deformation and material jetting would occur. The second factor would be due to the use of a gun step size. Since particle flow rate and velocity decrease as a function of the radial position from the center of the nozzle, using a gun step size would cause more variability in particle velocity. Unlike conditions $4_{\text {Fast }}$ and $4_{\text {Slow }}$, in which the microstructural observations were carried out in regions that received the fastest impacting particle velocities, this would lead to a lower average particle velocity. Hence, a more porous coating would be expected.

The microhardness for conditions $4_{\text {Fast }}$ and $4_{\text {Slow }}$ were 207 and $161 \mathrm{HV}$, respectively. The percent difference in microhardness was calculated to be approximately 22. For each of the conditions, the total spray time was identical with a time of about $15 \mathrm{~s}$. There are several possible explanations for the observed difference in microhardness between the two conditions. First, the increased presence of oxides and nitrides in condition $4_{\text {slow }}$ (which will be discussed in detail later) could have induced relatively weaker interparticle bonding because these enhanced oxide and nitride layers could restrict the plastic deformability of the titanium particles and subsequently, this could decrease the coating microhardness. However, due to the denser coating found in condition $4_{\text {Slow }}$, this indicates that more plastic deformation had occurred in comparison to condition $4_{\text {Fast }}$. The most likely explanation for such behavior would be that since the resultant average particle velocity was fairly high $(805 \mathrm{~m} / \mathrm{s})$ along with the relatively higher substrate temperature $\left(496^{\circ} \mathrm{C}\right)$ for condition $4_{\text {Slow }}$, breakdown of the oxide and nitride layers upon particle impact was possible. This facilitated the plastic deformation of the titanium particles and consequently, a denser coating was produced. Thus, this reduces the likelihood of the decreased coating microhardness caused by weaker interparticle bonding. Second, upon particles impacting on previously deposited particles, a tamping effect would occur, in which the initially sprayed particles would be further flattened and strain hardened by the subsequent impacting particles. Consequently, the coating microhardness would increase. However, when comparing conditions $4_{\text {Fast }}$ to $4_{\text {Slow }}$, even though condition $4_{\text {Fast }}$ had 30 times more gun passes than condition $4_{\text {Slow }}$, since the gun traverse speed for condition $4_{\text {Slow }}$ was 30 times slower, the number of particles impacting at a particular point in the coating would be the same for both the conditions. Thus, condition $4_{\text {Fast }}$ would not have an amplified tamping effect compared to condition $4_{\text {Slow }}$. Consequently, this suggests that the difference in microhardness could not be due to a difference in the number of gun passes. Third, the strain hardening 

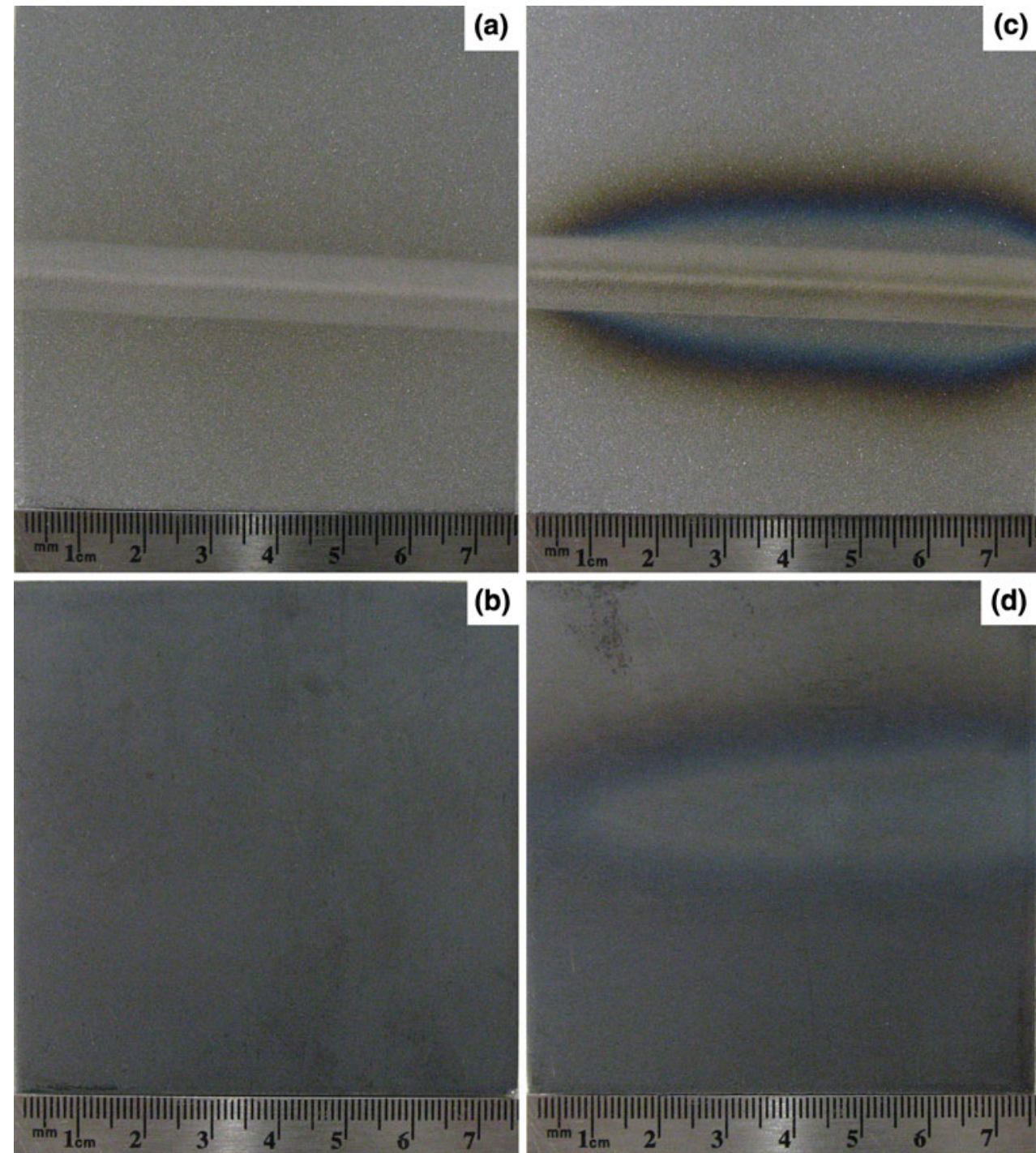

Fig. 9 Front view of as-sprayed single line Ti coating for conditions $4_{\text {Fast }}(a), 4_{\text {Slow }}(c)$, and their respective rear views (b, d)

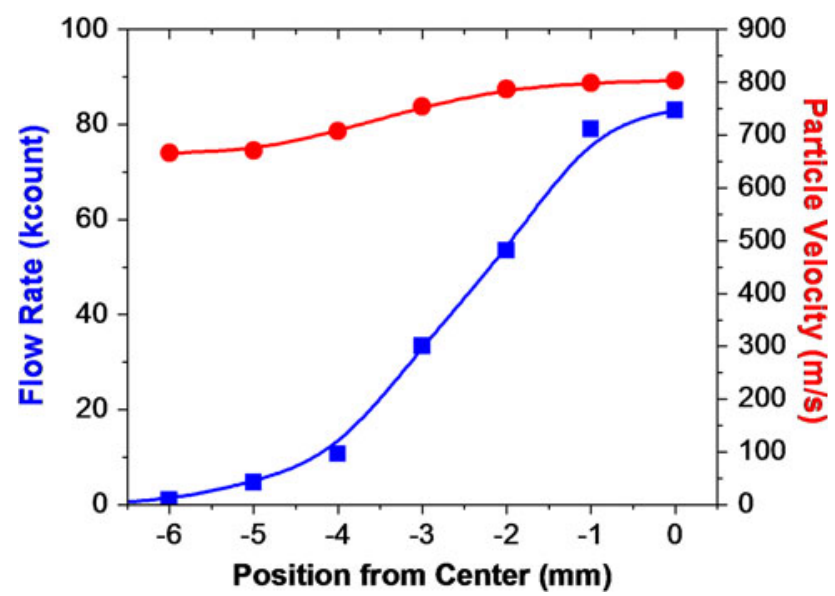

Fig. 10 Particle flow rate and velocity as a function of the radial position from the center of the nozzle

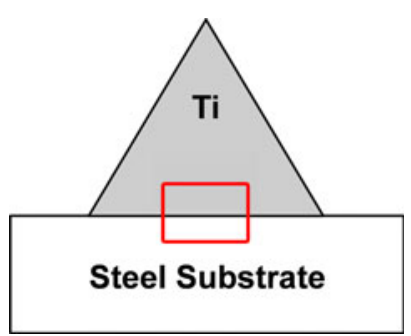

Fig. 11 Schematic representation of a cross-section of a thick single line coating

phenomenon can be described on the basis of dislocationdislocation strain field interactions (Ref 40). There is a general acceptance that dislocation density in a metal increases with plastic deformation and that resistance to dislocation motion by other dislocations produces harder 

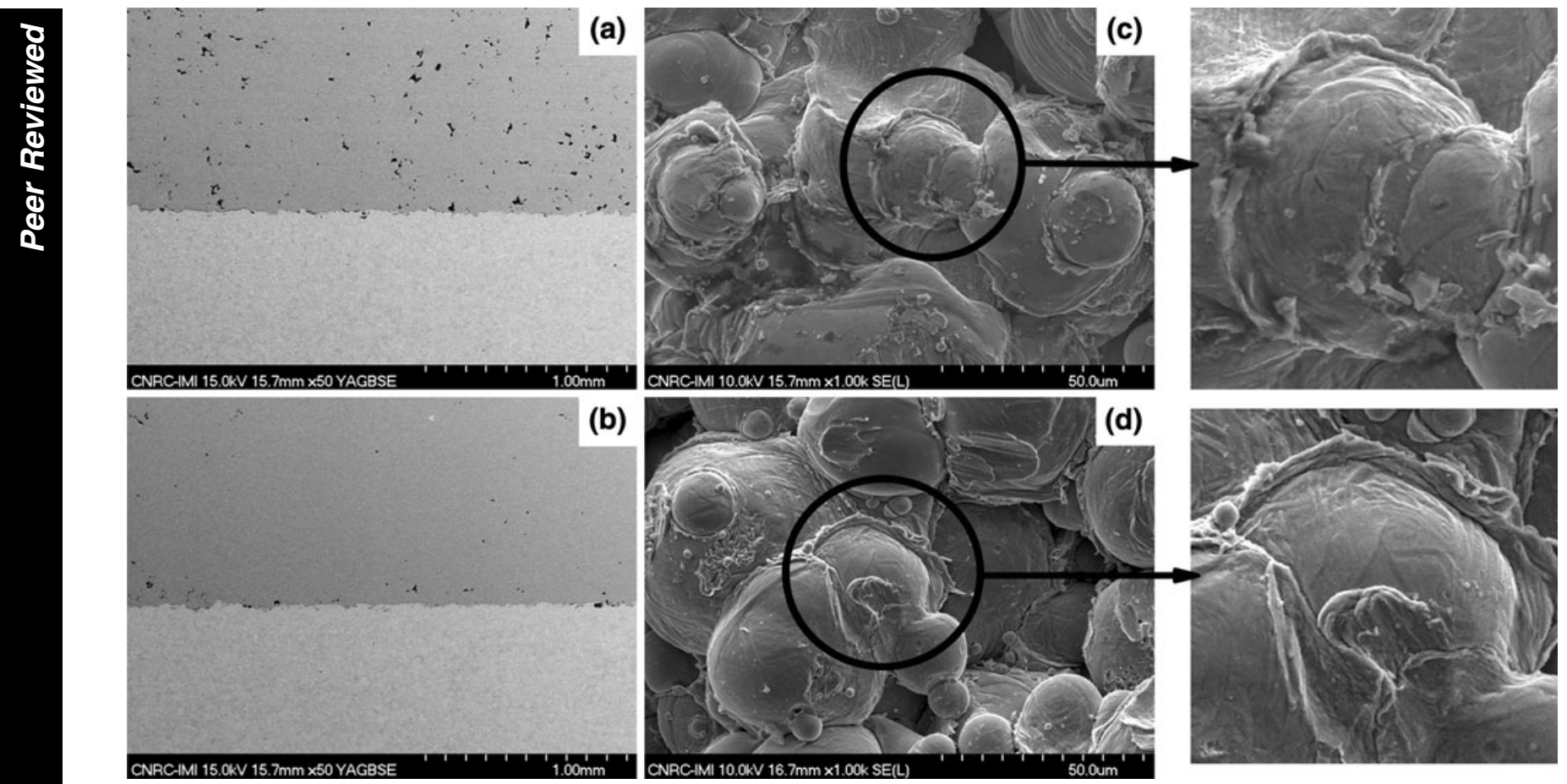

Fig. 12 Coating cross-section and surface top view, respectively, of condition $4_{\text {Fast }}(a, c)$ and $4_{\text {Slow }}$ (b, d)

metals. Additionally, it is well known that commercially pure titanium is entirely composed of $\alpha$ phase at room temperature and would undergo a phase transformation from $\alpha$ to $\beta$ phase when a temperature of $882.5^{\circ} \mathrm{C}$ is reached. One major characteristic of phase transformation in metals is that upon re-entering the previously worked state (i.e., $\alpha$ phase $\rightarrow \beta$ phase $\rightarrow \alpha$ phase), the dislocations previously generated in that phase would dissipate. Thus, when the number of dislocations significantly decreases due to phase transformation, a metal softening effect would be expected. In the case of condition $4_{\text {Slow }}$, since titanium has a relatively high heat capacity and low thermal conductivity, it could be possible that upon particle impact, the temperature of the particles reached the phase transformation temperature (i.e., $\alpha$ phase $\rightarrow \beta$ phase). However, due to the nature of the cold gas dynamic spray process, the cooling rate of impacted particles is exceptionally fast such that the occurrence of a phase transformation (i.e., $\beta$ phase $\rightarrow \alpha$ phase) would be highly improbable (Ref 16). Thus, the probability of the observed microhardness reduction for condition $4_{\text {slow }}$ due to phase transformation is low. Nonetheless, to confirm this, further coating microstructural investigation (i.e., TEM observations) would be required. Fourth, titanium grain refinements (several tens of nanometers in grain size) and homogeneous and randomly orientated, equiaxed nanograins have been observed in studies on commercially pure titanium warm sprayed splats (Ref 16) and cold sprayed coatings (Ref 41). For the former, the findings were explained by the dynamic recrystallization induced by severe mechanical deformation, while the latter findings were explained by the dynamic recovery, rotational dynamic recrystallization, and static recovery. Static recovery is defined as the reduction or removal of strain hardening effects (Ref 42) as a result of enhanced atomic diffusion at an elevated temperature which relieves some of the stored internal strain energy by virtue of dislocation motion in the absence of an externally applied stress (Ref 40). It is generally accepted when studying the flow behavior of hot deformed metals [i.e., steel (Ref 43) and near- $\alpha$ titanium alloys (Ref 44 )] that $20 \%$ metal softening can be attributed to static recovery. Based on this assumption as well as the previously reported studies on warm sprayed titanium splats (Ref 16) and cold sprayed titanium coatings (Ref 41), it would be more likely that the observed microhardness decrease for condition $4_{\text {Slow }}$ ( $22 \%$ softer than condition $4_{\text {Fast }}$ ) would be due to the predominant annealing effect of static recovery, although dynamic recovery and dynamic recrystallization could also have occurred during the particle deposition process.

As reported by Gulizia et al. (Ref 12), oxidation and nitridation might occur with increasing inlet gas temperature. To address this for different substrate temperatures, XPS measurements were performed for conditions $4_{\text {Fast }}$ and $4_{\text {slow }}$ for the same area of interest (in the center of the sample). The cross-section surfaces were ion sputteretched for $15 \mathrm{~min}$ on the analyzed area prior to data acquisition to remove surface oxides and contaminants. The resulting normalized $\mathrm{Ti} 2 \mathrm{p}$ spectra are shown in Fig. 13. For better comparison of the two spectra, Shirley background has been subtracted using the Casa XPS software. The charge effect on oxidized samples has been corrected based on position of $\mathrm{C} 1 \mathrm{~s}$ peak situated at $284 \mathrm{eV}$. For the sample deposited with a traverse speed of 


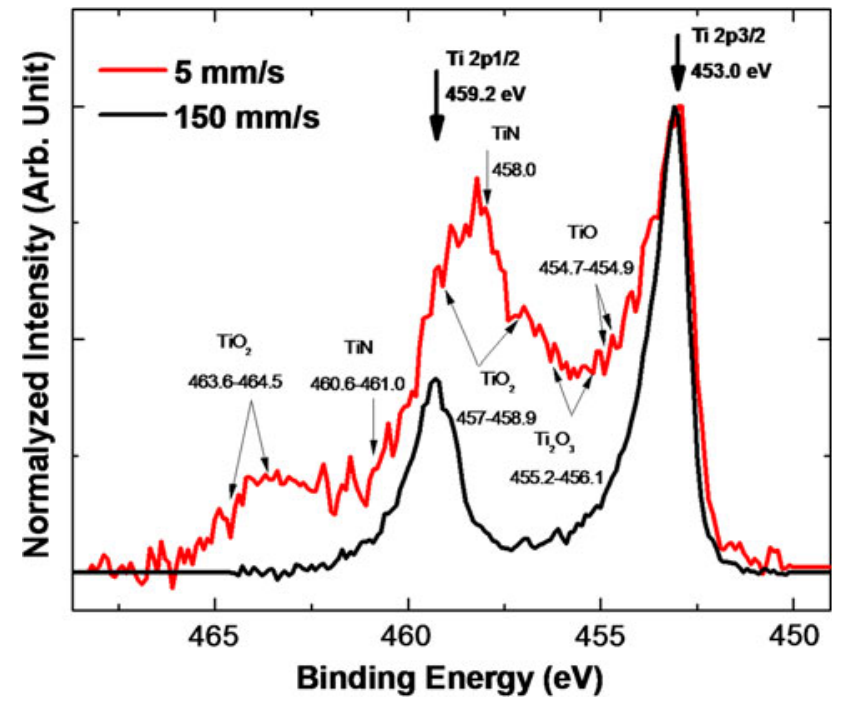

Fig. 13 Ti $2 p$ high-resolution spectra XPS profiles for conditions $4_{\text {Fast }}$ and $4_{\text {Slow }}$

$150 \mathrm{~mm} / \mathrm{s}\left(4_{\text {Fast }}\right)$, Ti $2 \mathrm{p} 1 / 2$ and Ti $2 \mathrm{p} 3 / 2$ peaks have been observed, located at 459.2 and $453.0 \mathrm{eV}$, respectively. In the case of condition $4_{\text {slow }}$, a group of additional peaks with higher binding energy was observed. Based on the XPS peaks database (Ref 45, 46), these additional peaks are associated with the presence of $\mathrm{Ti}$ oxides and $\mathrm{Ti}$ nitrides in the sample deposited at the lower gun traverse speed (higher substrate temperature). The approximate positions of $\mathrm{TiN}, \mathrm{TiO}$, and $\mathrm{TiO}_{2}$ peaks are indicated in Fig. 13. It is obvious that the low resolution of the obtained XPS spectra does not allow the decomposition of all spectral oxide and nitride components. However, it is clear that the $4_{\text {Slow }}$ sample contains significantly more $\mathrm{Ti}$ oxides and nitrides with respect to the $4_{\text {Fast }}$ sample.

This phenomenon of the efficient reaction between $\mathrm{Ti}$ and surrounding gas containing oxygen and nitrogen is most likely due to the much higher substrate temperature in the case of $4_{\text {Slow }}\left(496{ }^{\circ} \mathrm{C}\right)$ compared to $4_{\text {Fast }}\left(186{ }^{\circ} \mathrm{C}\right)$. Despite the significant increase in $\mathrm{Ti}$ oxides and nitrides concentration, the coating remained of good quality with regards to the level of porosity, particularly with the low level of porosity found for $4_{\text {slow }}$. However, further investigation is required to ascertain the effect of oxidation and nitridation on other important coating characteristics, such as coating bond strength. Nevertheless, based on porosity level, it seems more beneficial to cold spray titanium coatings using a slower gun traverse speed. Although, this only holds true for thick single line coatings because when a gun step size is used along with a relatively slow traverse speed, multiple peaks would be formed throughout the coating. Each individual peak would be triangular-shaped, similar to the schematic representation shown in Fig. 11. As mentioned before, particles colliding on the outer edges of the triangle would impact at an angle and consequently, this would achieve an effective impact velocity lower than those impacting perpendicularly to the substrate during each pass. Thus, a higher level of coating porosity would be expected on the outer edges.
Thus far, the effect of substrate temperature was investigated. Another line of research would be to investigate the effect of particle temperature in order to assess its influence on cold sprayed Ti coatings. For instance, this could be achieved by altering the cold spray gun prechamber configuration or by employing an external gas heater to raise the temperature of Ti particles. This will be addressed in the near future.

\subsection{Cold Spraying Titanium Coating at Maximum Particle Velocity Achieved with He}

In order to maximize titanium particle velocity sprayed with $\mathrm{He}$, a specially designed polymer nozzle for helium gas VH70 (ASB Industries Inc., Barberton, USA) was used to produce a sample at the maximum particle velocity. The configurations of the VH70 nozzle consist of a divergent part with a length of $105.5 \mathrm{~mm}$, an exit diameter of $3.7 \mathrm{~mm}$, and an exit to throat area ratio of 4.7.

For this experiment, the inlet gas pressure and temperature were set to the maximum operating conditions of $4 \mathrm{MPa}$ and $350{ }^{\circ} \mathrm{C}$, respectively, considering the system and nozzle limitations. At these propelling gas parameters, the particle velocity profile as a function of the stand-off distance was measured and the optimal position was determined to be $8 \mathrm{~cm}$. The gun traverse speed was set to $330 \mathrm{~mm} / \mathrm{s}$ and 10 passes were applied on a mild steel plate with a powder feeding rate of approximately $20 \mathrm{~g} / \mathrm{min}$. The average particle velocity was $1173 \mathrm{~m} / \mathrm{s}$ and the substrate temperature was approximately $73{ }^{\circ} \mathrm{C}$. It is worth noting that the velocity obtained here was significantly higher than $900 \mathrm{~m} / \mathrm{s}$ as reported by Zahiri et al. (Ref 28). This would more likely be due to the difference in nozzle design.

Figure 14(a) and (b) shows the as-polished cross-section and the surface top view of the coating, respectively. A DE of $100 \%$ was achieved. The resulting coating was fully dense with $0 \%$ porosity measured by image analysis. The microhardness values were 189 and $206 \mathrm{HV}$ for the top and bottom regions of the coating, respectively. Figure 14(b) clearly revealed the immense particle impingements, with material jetting surging almost to the full height of the particles. Figure 15, a magnified micrograph of Fig. 14(b), revealed nano-sized spherical particles which were not present in any of the other conditions $\left(1_{\mathrm{N}_{2}}, 1_{\mathrm{He}}, 2_{\mathrm{N}_{2}}, 2_{\mathrm{He}}, 3_{\mathrm{N}_{2}}, 3_{\mathrm{He}}, 4_{\text {Fast }}\right.$, and $\left.4_{\text {slow }}\right)$. One possible explanation of the formation of these particles could be the local melting and rapid solidification of pure titanium, as proposed by Bae et al. (Ref 35). It can be hypothesized that upon particle impact, plastic deformation and material jetting take place, and if the heat generated is large enough, molten titanium droplets will form at the apex of the jetted material. Subsequently, these projected droplets will rapidly cool and solidify, landing considerably away from the initial impact zone. Similar results were reported by Bae et al. (Ref 35) in which a pure titanium coating was produced on a mild steel substrate using an inlet He gas of $600{ }^{\circ} \mathrm{C}$ and a pressure of $1.5 \mathrm{MPa}$. However, the cold spray system and nozzle configuration used in their work differed from this study. In their work, it was also claimed 

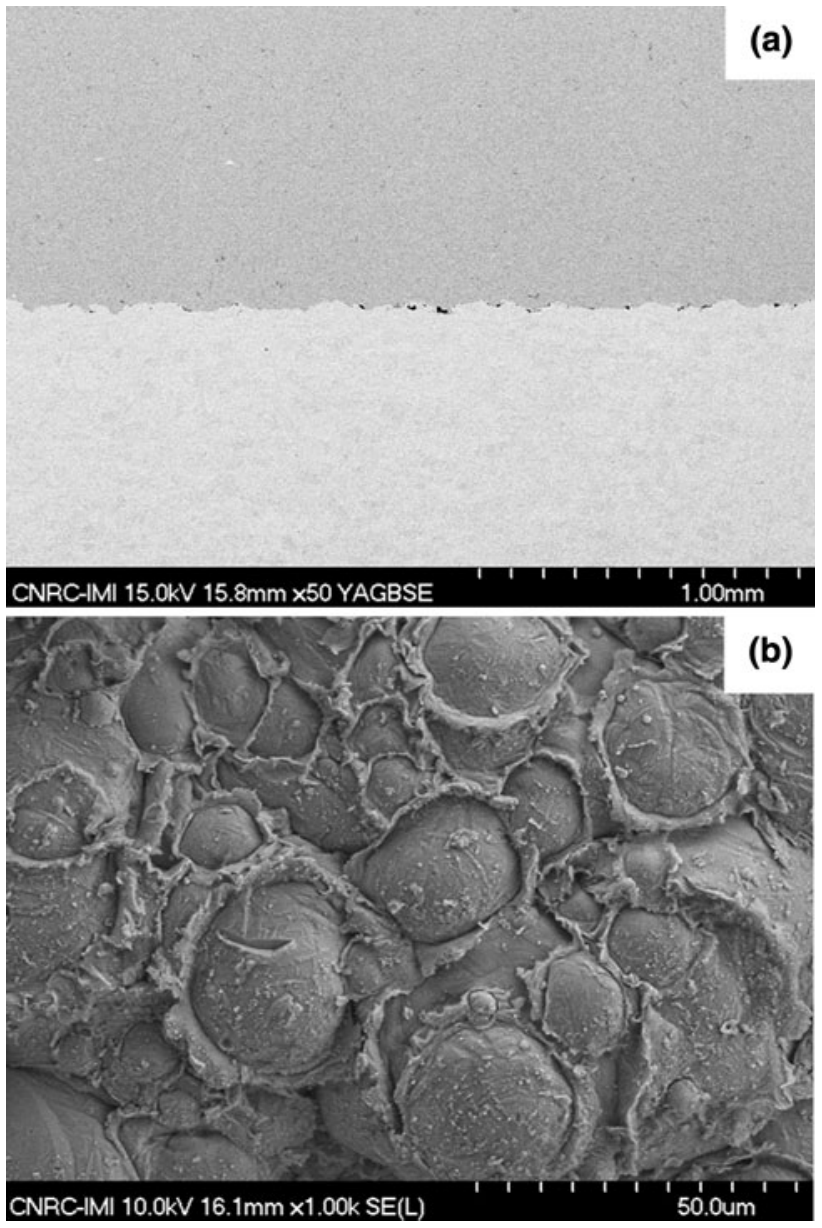

Fig. 14 (a) As-polished titanium coating cross-section sprayed at $1173 \mathrm{~m} / \mathrm{s}$ and (b) the corresponding coating surface top view

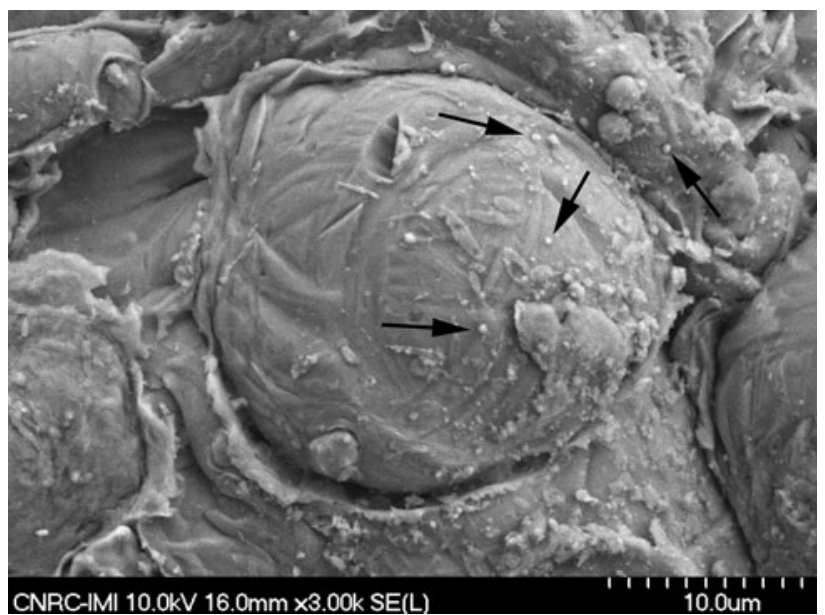

Fig. 15 Magnified coating surface top view of Fig. 14(b)

that local melting occurred as nano-sized spherical particles were found on the coating surface. This only occurred in their maximum velocity condition $(950 \mathrm{~m} / \mathrm{s})$. With respect to our findings, the fact that nano-sized particles were only present when the particle velocity was $1173 \mathrm{~m} / \mathrm{s}$ (condition 5) and not for any of the other conditions (which at most reached $812 \mathrm{~m} / \mathrm{s}$ ) indicates that there is a distinct difference between material jetting and metal melting. At higher particle velocities, a large amount of kinetic energy would be generated and this would result in severe deformation of the particles (Ref 35). Consequently, a larger adiabatic shear instability region would form (Ref 35$)$. As a result, more impacting particles would be able to reach a temperature much closer to the melting point of pure titanium (Ref 35). Thus, for metal melting to occur, material jetting is a necessary but not sufficient condition such that upon impact, the material jetting created by the plastically deformed titanium particles must contain enough heat in order for molten droplets and hence, nano-sized particles to form.

Although these results tend to demonstrate that $\mathrm{He}$ is required to produce fully dense and thick titanium coatings, on an industrial production scale, using $\mathrm{He}$ may not be economically viable for most applications due to its much higher cost as opposed to $\mathrm{N}_{2}$. As such, further research should still be performed on improving as-sprayed titanium coatings using nitrogen gas. Alternatively, industrial scale helium recovery systems could be considered to perform cold spray using $\mathrm{He}$ at a fraction of the cost.

\section{Conclusions}

The influence of helium and nitrogen gases on the properties of cold gas dynamic sprayed pure titanium coatings was investigated. For this study, spray parameters were adjusted to obtain similar particle velocities with both $\mathrm{He}$ and $\mathrm{N}_{2}$ as the propelling gases. The effect of substrate temperature was also investigated by altering the gun traverse speed while spraying with the same inlet gas conditions. In addition, a titanium coating was produced using $\mathrm{He}$ at an optimized particle velocity.

It was concluded that:

(1) For the same particle impact velocity, DE and density were mostly a function of surface temperature and/or impacting particle temperature. If a much higher inlet gas temperature was used, coatings produced with nitrogen were denser and obtained a higher DE than those produced with helium. This was due to a greater amount of consolidated region in between the particles and to the material jetting as a result of higher surface temperature.

(2) At a low particle velocity, loosely bonded particles can be removed from the surface if the gas pressure is high enough. At $3 \mathrm{MPa}$, evidence of detached particles were shown while at $0.5 \mathrm{MPa}$, no such evidence could be seen.

(3) A slower gun traverse speed, while maintaining all other spray parameters constant, increased the substrate temperature. The resulting coating was denser and softer. In all likelihood, this reduced microhardness 
of approximately $22 \%$ would be due to the annealing effect of static recovery, although dynamic recovery and dynamic recrystallization could also have occurred during the particle deposition process.

(4) XPS depth profile investigation revealed that more oxidation and nitridation occurred at the higher substrate temperature (i.e., at slower gun traverse speed).

(5) A thick and fully dense cold sprayed titanium coating was achieved using He with optimized spray parameters and nozzle.

\section{Acknowledgments}

The cold spray equipment used for this study was funded by CFI project number 8246, McGill University (Montreal, Canada) with the support of Cold Gas Technology $\mathrm{GmbH}$, Tecnar Automation Ltd., and Polycontrols Technologies Inc. The authors acknowledge the support of NSERC strategic grant and would like to thank C. Chabanier from INRS-EMT for XPS acquisitions and $\mathrm{J}$. F. Alarie, F. Belval, B. Harvey, M. Lamontagne, and M. Thibodeau from NRC-IMI for their technical support. Additional appreciation goes toward D. Poirier and P. Vo for their insightful discussions.

\section{Open Access}

This article is distributed under the terms of the Creative Commons Attribution Noncommercial License which permits any noncommercial use, distribution, and reproduction in any medium, provided the original author(s) and source are credited.

\section{References}

1. R.E. Blose, B.H. Walker, R.M. Walker, and S.H. Froes, New Opportunities to Use Cold Spray Process for Applying Additive Features to Titanium Alloys, Metal Powder Rep., 2006, 61(9), p 30-37

2. F. Gaertner, T. Schmidt, and H. Kreye, Present Status and Future Prospects of Cold Spraying, Mater. Sci. Forum, 2007, 534-536(1), p 433-436

3. J. Intrater, Cold Spray Technology-Prospects and Applications, Surf. Eng., 2002, 18(5), p 321-323

4. W. Wong, A. Rezaeian, E. Irissou, J.-G. Legoux, and S. Yue, Cold Spray Characteristics of Commercially Pure Ti and Ti-6Al4V, Adv. Mater. Res., 2010, 89(91), p 639-644

5. J. Pattison, S. Celotto, R. Morgan, M. Bray, and W. O'Neill, Cold Gas Dynamic Manufacturing: A Non-Thermal Approach to Freeform Fabrication, Int. J. Mach. Tools Manuf., 2007, 47(3-4), p 627-634

6. S. Cadney, M. Brochu, P. Richer, and B. Jodoin, Cold Gas Dynamic Spraying as a Method for Freeforming and Joining Materials, Surf. Coat. Technol., 2008, 202(12), p 2801-2806

7. V.K. Champagne, The Cold Spray Materials Deposition Process fundamentals and Applications, Wookhead, USA, 2007, p 362

8. R.G. Maev and V. Leshchynsky, Introduction to Low Pressure Gas Dynamic Spray: Physics \& Technology. Illustrated ed., Wiley-VCH, Weinheim, 2008, p 234
9. A. Papyrin, V. Kosarev, and S. Klinkov, Cold Spray Technology. Illustrated ed., Elsevier, Amsterdam, 2007, p 328

10. E. Irissou, J.G. Legoux, A.N. Ryabinin, B. Jodoin, and C. Moreau, Review on Cold Spray Process and Technology: Part I-Intellectual Property, J. Therm. Spray Tech., 2008, 17(4), p 495-516

11. G. Bae, K. Kang, H. Na, and C. Lee. Thermally Enhanced Kinetic Sprayed Titanium Coating: Microstructure and Property Improvement for Potential Applications, ITSC 2009, Las Vegas, NV, 2009

12. S. Guliziaa, B. Tiganis, M.Z. Jahedi, N. Wright, T. Gengenbach, and C. MacRae. Effects of Cold Spray Process Gas Temperature on CP Titanium Structure. ITSC 2009, Las Vegas, NV, 2009

13. M. Jahedi and S.H. Zahiri. Thermal Stability of Cold Spray Titanium Structures, ITSC 2009, Las Vegas, NV, 2009

14. J. Karthikeyan, C.M. Kay, J. Lindeman, P.S. Lima, and C.C. Berndt. Cold Spray Processing of Titanium Powder, Proceedings of the International Thermal Spray Conference, Montreal, QUE, 2000

15. W. Wong, A. Rezaeian, S. Yue, E. Irissou, and J.-G. Legoux. Effects of Gas Temperature, Gas Pressure, and Particle Characteristics on Cold Sprayed Pure Titanium Coatings, ITSC 2009, Las Vegas, NV, 2009

16. K. Kim, M. Watanabe, J. Kawakita, and S. Kuroda, Grain Refinement in a Single Titanium Powder Particle Impacted at High Velocity, Scr. Mater., 2008, 59(7), p 768-771

17. K. Kim, M. Watanabe, K. Mitsuishi, K. Iakoubovskii, and S. Kuroda, Impact Bonding and Rebounding Between Kinetically Sprayed Titanium Particle and Steel Substrate Revealed by HighResolution Electron Microscopy, J. Phys. D, 2009, 42(6), 065304 $(5 \mathrm{p})$

18. C.J. Li and W.Y. Li, Deposition Characteristics of Titanium Coating in Cold Spraying, Surf. Coat. Technol., 2003, 167(2-3), p 278-283

19. W.Y. Li, C. Zhang, X. Guo, J. Xu, C.J. Li, H. Liao, C. Coddet, and K.A. Khor, Ti and Ti-6Al-4V Coatings by Cold Spraying and Microstructure Modification by Heat Treatment, Adv. Eng. Mater., 2007, 9(5), p 418-423

20. R.S. Lima, A. Kucuk, C.C. Berndt, J. Karthikeyan, C.M. Kay, and J. Lindemann, Deposition Efficiency Mechanical Properties and Coating Roughness in Cold-Sprayed Titanium, J. Mater. Sci. Lett., 2002, 21(21), p 1687-1689

21. T. Marrocco, D.G. McCartney, P.H. Shipway, and A.J. Sturgeon, Production of Titanium Deposits by Cold-Gas Dynamic Spray: Numerical Modeling and Experimental Characterization, J. Thermal Spray Technol., 2006, 15(2), p 263-272(10)

22. T. Novoselova, P. Fox, R. Morgan, and W. O'Neill, Experimental Study of Titanium/Aluminium Deposits Produced by Cold Gas Dynamic Spray, Surf. Coat. Technol., 2006, 200(8), p 2775-2783

23. T.S. Price, P.H. Shipway, and D.G. McCartney, Effect of Cold Spray Deposition of a Titanium Coating on Fatigue Behavior of a Titanium Alloy, J. Therm. Spray Tech., 2006, 15, p 507-512

24. A.E. Segall, A.N. Papyrin, J.C. Conway, Jr., and D. Shapiro, A Cold-Gas Spray Coating Process for Enhancing Titanium, JOM, 1998, 50(9), p 52-54

25. S.H. Zahiri, C.I. Antonio, and M. Jahedi, Elimination of Porosity in Directly Fabricated Titanium via Cold Gas Dynamic Spraying, J. Mater. Process. Technol., 2009, 209(2), p 922-929

26. S.H. Zahiri, D. Fraser, and M. Jahedi, Recrystallization of Cold Spray-Fabricated CP Titanium Structures, J. Thermal Spray Technol., 2008, 18(1), p 1-7

27. S.H. Zahiri, S.C. Mayo, and M. Jahedi, Characterization of Cold Spray Titanium Deposits by X-Ray Microscopy and Microtomography, Microsc Microanal, 2008, 14(3), p 260-266

28. S.H. Zahiri, W. Yang, and M. Jahedi, Characterization of Cold Spray Titanium Supersonic Jet. J. Thermal Spray Technol., 2008, 18(1), p 110-117

29. E. Irissou, J.-G. Legoux, B. Arsenault, and C. Moreau, Investigation of $\mathrm{Al}-\mathrm{Al}_{2} \mathrm{O}_{3}$ Cold Spray Coating Formation and Properties, J. Therm. Spray Tech., 2007, 16(5), p 661-668

30. A.N. Ryabinin, E. Irissou, J.-G. Legoux, and C. Moreau, Heat Exchange of Supersonic Jet with Obstacle in Cold Spray. VESTNIK SPbGU, 2009, Ser 1(1), p 123-128

. 
31. E. Irissou, J.-G. Legoux, A.N. Ryabinin, and C. Moreau. How Cold is Cold Spray? An Experimental Study of the Heat Transfer to the Substrate in Cold Gas Dynamic Spraying, Thermal Spray 2008: Proceedings of the International Thermal Spray Conference, 2008, Maastricht, The Netherlands

32. T. Stoltenhoff, H. Kreye, and H.J. Richter, An Analysis of the Cold Spray Process and Its Coatings, J. Therm. Spray Tech., 2002, 11(4), p 542-550

33. C.B. Henderson, Drag Coefficients of Spheres in Continuum and Rarefied Flows, AIAA J., 1976, 14(6), p 707-708

34. J.-G. Legoux, E. Irissou, S. Desaulniers, J. Bobyn, B. Harvey, W. Wong, E. Gagnon, and S. Yue. Characterization and Performance Evaluation of a Helium Recovery System Designed for Cold Spraying, ITSC 2010, 2010

35. G. Bae, S. Kumar, S. Yoon, K. Kang, H. Na, H.J. Kim, and C. Lee, Bonding Features and Associated Mechanisms in Kinetic Sprayed Titanium Coatings, Acta Mater., 2009, 57(19), p 56545666

36. T. Schmidt, H. Assadi, F. Gärtner, H. Richter, T. Stoltenhoff, H. Kreye, and T. Klassen, From Particle Acceleration to Impact and Bonding in Cold Spraying, J. Therm. Spray Tech., 2009, 18(5-6), p 794-808

37. H. Assadi, F. Gartner, T. Stoltenhoff, and H. Kreye, Bonding Mechanism in Cold Gas Spraying, Acta Mater., 2003, 51(15), p 4379-4394
38. G. Bae, Y. Xiong, S. Kumar, K. Kang, and C. Lee, General Aspects of Interface Bonding in Kinetic Sprayed Coatings, Acta Mater., 2008, 56(17), p 4858-4868

39. T. Schmidt, F. Gartner, H. Assadi, and H. Kreye, Development of a Generalized Parameter Window for Cold Spray Deposition, Acta Mater., 2006, 54(3), p 729-742

40. W.D. Callister and D.G. Rethwisch, Fundamentals of Materials Science and Engineering: An Integrated Approach, 3rd ed., Wiley, New York, 2008, p 882

41. G. Bae, K. Kang, J.J. Kim, and C. Lee, Nanostructure formation and its effects on the mechanical properties of kinetic sprayed titanium coating. Mater. Sci. Eng. A, 2010, 527(23), p 6313-6319

42. "ASM Handbook Volume 2: Properties and Selection: Nonferrous Alloys and Special-Purpose Materials," 10 ed., ASM Handbook, Vol. 2, ASM International, 1990, p 1328

43. A.I. Fernández, B. López, and J.M. Rodríguez-Ibabe, Relationship Between the Austenite Recrystallized Fraction and the Softening Measured from the Interrupted Torsion Test Technique, Scr. Mater., 1999, 40(5), p 543-549

44. P. Vo, M. Jahazi, and S. Yue, Recrystallization During Thermomechanical Processing of IMI834, Metall. Mater. Trans. A, 2008, 39(12), p 2965-2980

45. NIST X-ray Photoelectron Spectroscopy Database. 2010, http:// srdata.nist.gov/xps/

46. ThermoFisher Scientific. 2010, Available from: http://lasurface.com/ 